\title{
Utilizing Student-Generated Pictures for Formative Vocabulary Instruction
}

\author{
Charles J. Anderson \\ Kyushu Sangyo University \\ doi: http://dx.doi.org/10.7820/vli.v01.1.anderson
}

\begin{abstract}
Contemporary vocabulary learning strategies focus on the learner. This may overlook the effect good classroom instruction, such as formative feedback, can have on acquisition. Formative feedback is strongly correlated with positive learning outcomes because it provides explicit information the learner can use to move beyond what is known and towards a learning goal. Drawing pictures of target vocabulary is one activity that supports vocabulary acquisition while also promoting more formative feedback. Research indicates that the drawing of pictures can deepen understanding and improve recall. Furthermore, students' illustrations also facilitate the delivery of more specific feedback than more conventional vocabulary acquisition strategies, provided teachers use them effectively. This activity aids less proficient university students by facilitating better feedback and deepening existing vocabulary knowledge and improving recall.
\end{abstract}

Keywords: vocabulary learning; vocabulary acquisition; pictures; drawing; illustration; learning strategies.

\section{Background}

Numerous methods for effectively teaching vocabulary have been proposed in the second language acquisition (SLA) literature over the past 20 years. Schmitt (1997) groups them into two broad categories: discovering strategies for initial learning, and consolidation strategies for remembering and deepening understanding of previously encountered words. A majority of these strategies fall into the more important second category, and most have been shown to be effective. Relying only upon these consolidation strategies, however, risks disregarding other potentially beneficial features of classroom instruction that have been shown to strongly correlate with positive learning outcomes. Of particular interest is the role formative feedback can play in facilitating learning. In meta-analyses, formative feedback has been repeatedly shown to be one of the greatest predictors of learning outcomes (Hattie, 2009). Formative feedback is any information the learner can use to move beyond what is known, towards what they desire to know. However, until now the literature has not discussed teaching methods that facilitate this process. This paper proposes a classroom activity which could facilitate formative feedback from teachers to students, picture drawing, and details its use in a classroom setting over the course of a semester. 


\subsection{Using Picture Drawing for Formative Feedback in the Classroom}

One vocabulary learning strategy that provides repeated opportunities for formative feedback is drawing pictures in support of vocabulary acquisition. This activity asks students to attempt to capture the meaning of the target English word in a simple, quickly drawn picture. This strategy has been positively identified in the literature (Schmitt, 1997), but little research has investigated its efficacy. It is hypothesized that illustrations, similar to the keyword method (Nation, 2001), can improve recall by providing learners with mnemonics, but unlike keywords it has the added benefits of requiring less training, is quick, flexible, and can be used with any student who can put pencil to paper. Perhaps most importantly, it can provide teachers with clear information about learners' understanding of target words. Drawing pictures can also support vocabulary learning by repurposing existing L1 strategies, including personalization, elaboration, deeper semantic and lexical understanding as well as meta-cognitive approaches to study. These are strategies many low-proficiency students lack (Mochizuki, 1999), but can use, provided they receive adequate support.

An additional benefit of picture drawing is that it promotes more formative feedback from teacher to student. It allows the teacher to determine what aspects of word meaning the learner has obtained and what is yet to be mastered, which facilitates more effective feedback and learning. Studies have shown the teacher leading an activity often has a larger learning effect than any particular strategy (Timperley \& Alton-Lee, 2008). It is of course considerably more difficult to identify what makes a good teacher than a good task (Korthagen, 2004), but a major feature of effective instruction closely linked to positive learning outcomes is the use of formative feedback (Petty, 2006). Formative feedback is more effective than summative feedback (such as test results) because it provides explicit and specific instruction that enables a learner to engage with an activity, monitor their progress and, upon completion, move towards a new goal and increased self-regulation (Black \& William, 1998). The effectiveness of appropriate formative feedback to learning is reflected in consistently high effect sizes across numerous meta-analyses that see it as one of the most important contributors to learning (Hattie, 2009). If such feedback is critical to effective learning, then vocabulary acquisition strategies facilitating more effective feedback should promote positive learning outcomes. Picture drawing activities can facilitate such outcomes.

\section{The Activity}

This activity has been used successfully in low English proficiency (as measured by the TOEIC Bridge Test) Japanese university conversation classes. Before starting to draw pictures students need knowledge of, or access to, both the words under study and their L1 equivalents. Students were first required to study 40 words weekly and complete a vocabulary notebook containing the words, two of their most common L1 equivalents and example sentences for the highest-frequency words. After completing this preliminary step the picture drawing strategy was introduced. Training students on how to use the strategy was relatively simple, with a brief introduction outlining the approach. Students were then encouraged to reflect on how they acquired L1 logographic fluency to demonstrate how the strategy could support their current vocabulary study methods. Students were then provided with a variety of examples. They were next asked to identify good and poor

Vocabulary Learning and Instruction, 1(1), 37-43. 
exemplars and to support their opinions. Examples of symbolic shorthand were identified and promoted through examples that showed how different parts of speech might be represented visually. A demonstration of how to draw appropriate pictures using a think-aloud procedure was employed to ensure students understood the goal of the exercise: to use pictures to facilitate recall and deeper lexical understanding. Much of this consisted of what Carless (2007) has labeled "preemptive formative feedback" and was intended to avoid problems previously encountered and provide guidance to improve production of effective pictures.

The worksheet containing space for an English word, the Japanese translation and picture was then handed out. Students first attempted the task in the following order: (1) Write the target English word. (2) Write one unknown or poorly understood Japanese definition. (3) Draw a picture to promote recall and understanding of the target English word and the L1 translation. Extensive individualized feedback was provided to all students while engaged in the task to ensure students understood the strategy and how to implement it.

In order to gauge understanding, the L1 and L2 meanings were obscured and students were asked to produce the meaning with only the picture as a cue. Students who were unable to recall the L1 and L2 meanings were encouraged to create better pictures through more personalization or the addition of more detail. Students who were able to only recall the L1 meaning were asked to rehearse the L2 meaning more as they drew the picture. Students who were able to recall both the L1 and L2 meanings were encouraged to elaborate on the word's meaning, part of speech or usage. Words that were consistently difficult to recall or draw were identified and a think-out-loud procedure was used to model potential solutions to the entire class.

Students drew pictures of the remaining 40 words for homework. The following week a short 15-item, low-stakes test containing the previously studied words was then administered to provide students and teachers with summative feedback on progress. Students who performed poorly on these tests received a further round of formative feedback on their previous drawings. To ensure student participation, appropriately completed homework received $2 \%$ per assignment $(2 \% \times 10=20 \%)$ of the final grade. Incomplete homework received no score, but was required to be completed in order to receive a final passing grade.

\subsection{Facilitating Feedback}

All feedback provided was focused on improving the student's ability to use pictures to recall target English words. Students who were able to successfully recall both the target word and the L1 equivalent were then encouraged to use the target word productively. Students who were able to recall the L1 meaning but not the L2 target were encouraged to process the task using more L2. Students who were unable to recall the target L2 word, nor its L1 equivalent were encouraged to engage more deeply in the task and were provided with more instruction. Students who provided incorrect answers were asked to refine their picture with more detail. An examination of students' drawings and teacher-student interactions should illustrate how formative feedback was used to support the activity:

An important first step in promoting deeper vocabulary acquisition is to ensure students have established a strong L1-L2 link (Schmitt, 2008). Monitoring was conducted by covering the target word and translation and asking students to

Vocabulary Learning and Instruction, 1(1), 37-43. 
recall the target word, which in itself is a valuable learning strategy (Nation, 2001). A quick glance at student A's pictures (Figure 1(a-f)) allowed for a quick evaluation of depth of engagement with the task. Pictures indecipherable to the teacher such as Figure 1a are a good focus for feedback. In this instance, student A was able to successfully recall the word "true" and a follow-up question as why recall was possible elicited student A's love for abstract art and how it felt "true" which demonstrated proper engagement with the activity.

(a)

(b)

(c)

(d)

(e)

(f)

\begin{tabular}{|c|c|c|c|c|c|}
\hline \begin{tabular}{l|l}
02 & $\begin{array}{l}\text { true } \\
\text { (形'榕言习) }\end{array}$ \\
\end{tabular} & 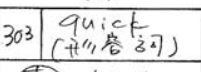 & \begin{tabular}{|l|l|l}
304 & fun \\
\end{tabular} & 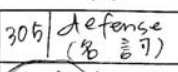 & $306 \mid \begin{array}{cc}\text { treatment } \\
\text { (名 } & \text { 三丨) }\end{array}$ & 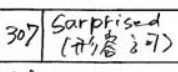 \\
\hline 真量の/案際の & (東1)/すばやい & 楽しむ & 防得于/国防 & 治源/治滰法 & 警へた \\
\hline 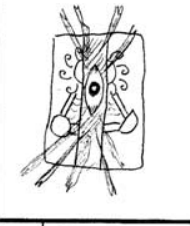 & 3 & $\sqrt{T} \vec{b}$ & \& & $\pi$ & \\
\hline
\end{tabular}

(g)

(h)

(i)

(j)

(k)

(I)

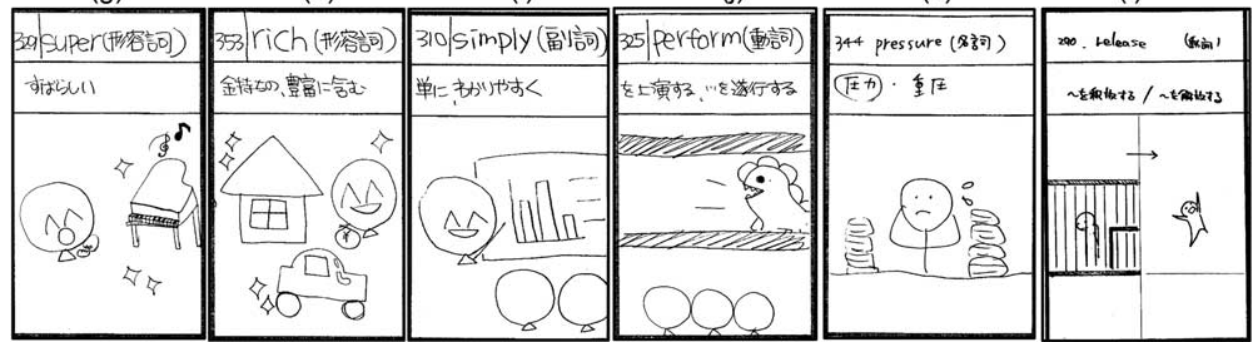

Figure 1. Examples of student-generated pictures.

Comparing multiple pictures also provides evidence of students' deeper lexical knowledge which is seen as a potential contributor to vocabulary learning (Oxford \& Crookall, 1990). Student B's illustrations (Figure 1g and h) show grammatical marking, whereas student A's illustrations (Figure $1 \mathrm{~b}$ and $\mathrm{f}$ ) show none. A recall check confirmed student B was able to recall both words in their correct L2 adjectival form, explaining that the "stars" in both pictures represented "ideas not things." Student A after recalling Figure 1b as "run," not "quick," explained it looked like a person running. Each student's response to the retrieval cue stimulated a deeper teacher-student discussion into how their pictures might be improved to provide better retrieval and deepen grammatical understanding. As student B had demonstrated the ability to process pictures for grammar, the feedback focused on extending this processing to other words by asking "Could you use this strategy for other kinds of words?" This interaction encouraged B to develop symbols for verbs and adverbs, later adding detail (not shown) to Figure 1i and j. Student A's feedback was more reflective in tone; responding to the question of "Why was 'surprised' (Figure 1f) easier to recall than 'quick' (Figure 1b)?" Student A suggested erasing the extra detail in "quick" to make it look more like "surprised." This in turn led to a comparison of Figure $1 \mathrm{~d}-\mathrm{f}$ and a discussion of how words might be visually tagged for grammar. In this way students' responses, correct and incorrect, in conjunction with pictures, provided both student and educator an opportunity to discuss more efficient task processing, which was potentially beneficial for student learning and teaching practice. 
Pictures facilitate delivering motivating, formative feedback in support of improved meta-cognitive awareness (Schmitt, 1997) relatively easily. When student B was unable to recall either the Japanese or English meaning of Figure 1i, the following interaction resulted:

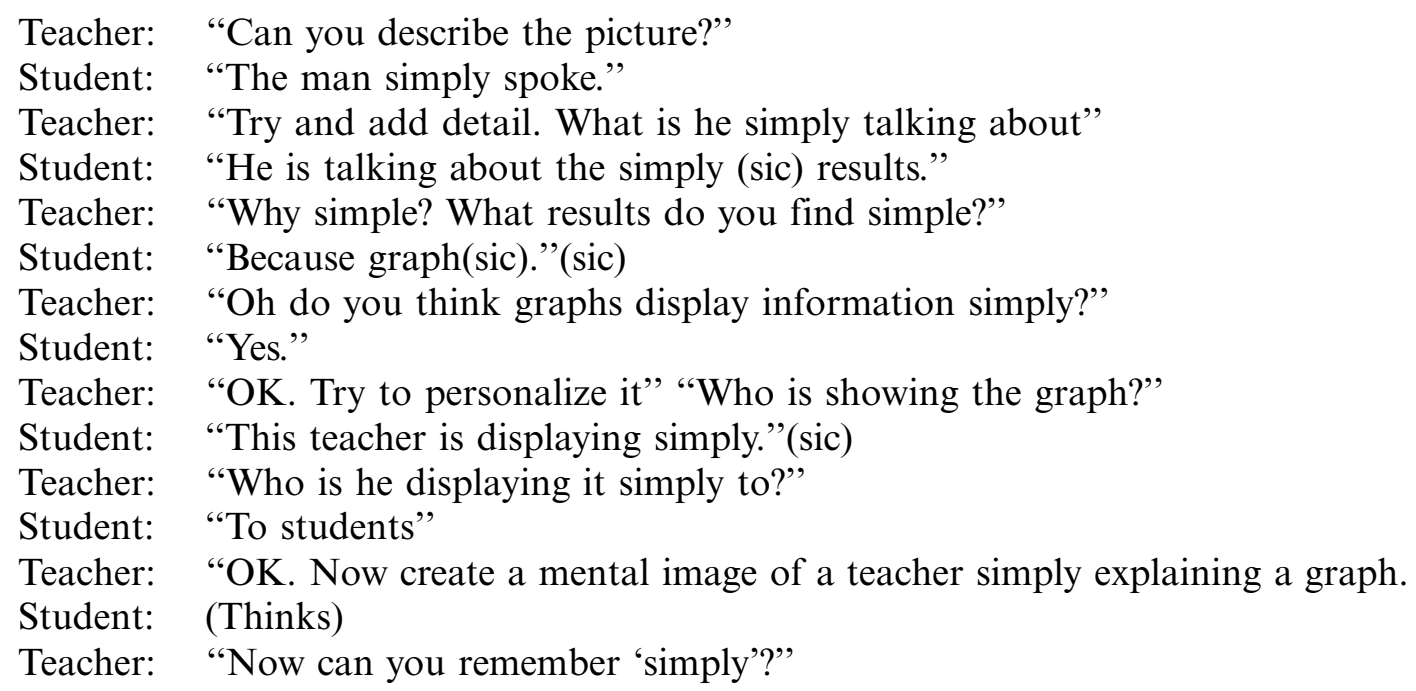

When the student answered affirmatively the teacher was free to move on. A quick re-check later demonstrated the student's fast and accurate recall and evidence of engagement.

Pictures easily support the addition of more detail to help contextualize semantic elaboration (Oxford \& Crookall, 1990), or integrate the word into an existing schema (Sökmen, 1997). Initially, the picture shown in Figure 1j consisted of only a stick figure and the "sweat." A quick retrieval check displayed confusion between "hot" and "pressure" which led to the following interaction:

Teacher: (Pointing to the picture in Figure 1k) "What is this word in Japanese?"

Student: “あつい” (Hot).

Teacher: "Why do you think so?"

Student: "He looks hot."

Teacher: (Revealing the Japanese and English) "What's the difference between "hot" and "pressure?"

Student: (No answer)

Teacher: "When do you feel pressure?"

Student: "When I do homework."

Teacher: "Why not draw when you feel pressure?"

As a result of this interaction, student $\mathrm{C}$ included books on either side to represent homework, and a subsequent check showed no further confusion between "hot" and "pressure".

Often students who displayed an ability to quickly recall the Japanese meaning but failed to recall the target English word reported thinking about the meaning while drawing, but when questioned further indicated they were thinking about the Japanese meaning. The suggestion to think about and repeat the word in English prior to and while drawing the picture appeared to result in better recall, but more research will be needed to confirm this observation. 
These exchanges are just a small sample of the formative feedback students received while engaged in the drawing activity. While the author acknowledges other activities, such as writing personalized sentences may also increase opportunities for feedback, pictures are unique because all students, regardless of L2 proficiency, can express the degree to which they understand a word. It can also be argued that the drawing in Figure 11 provides better evidence of comprehension of the word "release" than an equivalent example sentence such as the man was happy when he was released from jail. Pictures also provide more insight into the individuals' learning process with accordingly increased opportunities for feedback on task processing, comprehension, and directions for future study.

\section{Conclusion}

The drawing of pictures to facilitate better word learning is a relatively simple but powerful and underutilized learning strategy. However strategies alone are not enough; the role of an efficient teacher and engaged students cannot be underestimated $(\mathrm{Gu}, 2003)$. What is then left is the need for a level-appropriate, engaging strategy that also serves to facilitate teacher-student feedback. Drawing pictures meets these criteria, and offers educators and learners a novel, yet effective activity with which to support the complex and difficult task of acquiring word knowledge.

\section{References}

Black, P., \& William, D. (1998). Assessment and classroom learning. Assessment in Education: Principles, Policy \& Practice, 5(1), 7-74. doi:10.1080/ 0969595980050102

Carless, D. (2007). Conceptualizing pre-emptive formative assessment. Assessment in Education: Principles, Policy \& Practice, 14(2), 171-184. doi:10.1080/ 09695940701478412

Gu, P.Y. (2003). Vocabulary learning in a second language: Person, task, context, and strategies. TESL-EJ, 7(2), 1-26. Retrieved from: http://tesl-ej.org/ej26/a4.html

Hattie, J. (2009). Visible learning: A synthesis of over 800 meta-analyses relating to achievement. London, New York: Routledge.

Korthagen, F. (2004). In search of the essence of a good teacher: Towards a more holistic approach in teacher education. Teaching and Teacher Education, 20(1), 77-97. doi:10.1016/j.tate.2003.10.002

Mochizuki, A. (1999). Language learning strategies used by Japanese university students. RELC Journal, 30(2), 101-113. doi:10.1177/003368829903000206

Nation, I.S.P. (2001). Learning vocabulary in another language. Cambridge: Cambridge University Press.

Oxford, R., \& Crookall, D. (1990). Vocabulary learning: A critical analysis of techniques. TESL Canada Journal, 7(2), 11-30.

Petty, G. (2006). Evidence based teaching. Cheltenham: Nelson Thornes. 
Schmitt, N. (1997). Vocabulary learning strategies. In N. Schmitt (Ed.), Vocabulary: Description, acquisition, and pedagogy (pp. 199-227). Cambridge: Cambridge University Press.

Schmitt, N. (2008). Review article: Instructed second language vocabulary learning. Language Teaching Research, 12(3), 329-363. doi:10.1177/1362168808089921

Sökmen, A. (1997). Current trends in teaching second language vocabulary. In N. Schmitt \& M. McCarthy (Eds.), Vocabulary: Description, acquisition and pedagogy (pp. 237-257). Cambridge: Cambridge University Press.

Timperley, H., \& Alton-Lee, A. (2008). Reframing teacher professional learning: An alternative policy approach to strengthening valued outcomes for diverse learners. Review of Research in Education, 32(1), 328-369. doi:10.3102/ $0091732 X 07308968$ 